\title{
Use of heterologous antigens for the immunodiagnosis of abdominal angiostrongyliasis by an enzyme-linked immunosorbent assay
}

\author{
Renata Ben1', Rubens Rodrigues², Aventino Alfredo Agostini² ${ }^{2}$ Carlos Graeff-Teixeira ${ }^{1}{ }^{+}$ \\ ${ }^{1}$ Grupo de Parasitologia Biomédica, Laboratório de Parasitologia Molecular, Instituto de Pesquisas Biomédicas e \\ Laboratório de Biologia Parasitária, Faculdade de Biociências, Pontifícia Universidade Católica do Rio Grande do Sul, \\ Av. Ipiranga 6690, 90690-900 Porto Alegre, RS, Brasil 'Instituto de Patologia de Passo Fundo, Passo Fundo, RS, Brasil
}

Angiostrongylus costaricensis has a broad geographic distribution spanning from North to South America and the infections of vertebrates with this nematode can result in abdominal complications. Human infections are diagnosed by histological or serological methods because the isolation of larvae from feces is not feasible, as most parasites become trapped in intestinal tissues due to intense eosinophilic inflammation. Because A. costaricensis is difficult to maintain in the laboratory, an immunodiagnostic IgG enzyme-linked immunosorbent assay (ELISA) using antigens from the congeneric Angiostrongylus cantonensis species was evaluated against a panel of serum samples from patients who were histologically diagnosed with A. costaricensis infections. Sera from uninfected individuals and individuals infected with other parasites were used as controls. The sensitivity and specificity of the assay were estimated at $88.4 \%$ and $78.7 \%$, respectively. Because the use of purified or cloned antigens has not been established as a reliable diagnostic tool, the use of heterologous antigens may provide a viable alternative for the development of an ELISA-based immunodetection system for the diagnosis of abdominal angiostrongyliasis.

Key words: abdominal angiostrongyliasis - Angiostrongylus costaricensis - Angiostrongylus cantonensis - immunodiagnosis eosinophilic gastroenteritis - helminths

Human abdominal angiostrongyliasis (AA) is caused by infection by the intra-arterial nematode Angiostrongylus costaricensis that complete their sexual cycle in rodents. Humans are accidental hosts and the localization of adult worms inside mesenteric arteries leads to the development of inflammatory lesions (Graeff-Teixeira et al. 1991). AA has been diagnosed across Central and South America and isolated imported cases have been reported in Europe and the United States. Molecular diagnostic methods are important for diagnosing human disease because first-stage larvae can only be detected microscopically in the feces of the definitive host, rodents (Pena et al. 1995).

Angiostrongylus cantonensis is a metastrongylid nematode with a broad geographic distribution spanning from Asia, the Pacific Islands, Central America and more recently, South America. Adult worms live within the pulmonary arteries of definitive hosts (e.g. the black rat, Rattus norvergicus) following the maturation of late larval stages in the central nervous system. Accidental infections of humans may result in eosinophilic meningitis due to the inability of larvae to exit meningeal tissues (Wang et al. 2008).

The utilization of antigens for the immunodiagnosis of AA has been hindered by complications that are associated with maintaining the life cycle of $A$. costaricensis in

Financial support: CNPq (grants 300456/2007-7, 477260/2007-1), FAPERGS

CGT is a recipient of a CNPq PQ 1D fellowship.

+ Corresponding author: graeff.teixeira@gmail.com

Received 25 June 2010

Accepted 26 August 2010 the laboratory for use as a source of crude antigen. However, $A$. cantonensis can be maintained and propagated in the laboratory more effectively and can therefore provide large amounts of heterologous antigens; these antigens can be used to develop immunodiagnostic assays that detect cross-reactive $A$. costaricensis antibodies. This study evaluated the use of $A$. cantonensis antigens in a standardized enzyme-linked immunosorbent assay (ELISA) for the diagnosis of $A$. costaricensis infections.

\section{SUBJECTS, MATERIALS AND METHODS}

The parasite - A cantonensis was kindly provided by Professor Kentaro Yoshimura, Akita University Medical School, Japan. The parasite was maintained in the Parasitary Biology Laboratory of Pontifical Catholic University of Rio Grande do Sul (PUCRS), by perpetuating the infectious cycle in $R$. norvergicus and Biomphalaria glabrata that are used as definitive and intermediate hosts, respectively.

Animal handling - Animal experiments were carried out according to regulations that were established by the Brazilian College of Animal Experimentation and the protocol was approved by the University Ethical Committee for research involving human subjects.

Sera - Samples $(\mathrm{n}=26)$ from patients with histopathological diagnoses of $A$. costaricensis infections were used as positive controls (PC) (Graeff-Teixeira et al. 1991). These patients came from the states of RS, Santa Catarina and Paraná and they were diagnosed after surgical treatment for complicated courses of abdominal disease. Serum samples were collected from 1-8 weeks after the beginning of symptoms. A panel of 47 serum samples from patients with positive fecal diagnoses for at least one of the following parasites were included as specificity con- 
trols: Ascaris lumbricoides, hookworm, Entamoeba coli, Giardia duodenalis, Schistosoma mansoni, Strongyloides stercoralis and Trichuris trichiura. These patients lived in the urban areas of Rio de Janeiro, São Paulo or Recife and they were outside of the areas that are endemic for AA. Sera $(\mathrm{n}=11)$ from healthy students (without fever, abdominal pain or any other signs of systemic diseases) from PUCRS were also included as negative controls (NC).

Antigen preparation - Female A. cantonensis worms were removed from the pulmonary arteries and cardiac cavities of infected rats, washed in saline and stored at $-20^{\circ} \mathrm{C}$ until use. For antigen preparation, 60 worms were frozen in liquid nitrogen and homogenized until they were reduced to a fine powder. For protein extraction, $1 \mathrm{~mL}$ of $20-\mathrm{mM}$ $\mathrm{NaCl}$ Tris- $\mathrm{HCl}$ containing 1-mM phenylmethylsulphonylflouride (Sigma, St. Louis, MO), 1-mM Na-p-tosyl-L-lysine chloromethylketone TLCK (Sigma) and 1-mM ethylenediamine-tetra-acetic acid EDTA (Sigma) were added and the solution was sonicated three times for $2 \mathrm{~min}$ at $30 \%$ amplitude. The suspension was centrifuged twice at $12,000 \mathrm{~g}$ for $20 \mathrm{~min}$ at $4^{\circ} \mathrm{C}$ and the resulting soluble supernatant was stored at $-20^{\circ} \mathrm{C}$ until use. The protein concentrations were determined using the Bradford assay (Bradford 1976).

ELISA - The optimal antigen concentrations and serum dilutions for ELISAs were determined by titration and the optimal concentration of crude antigen was determined to be $5 \mu \mathrm{g} / \mathrm{mL}$. The assays were carried out by coating polystyrene plates with $100 \mu \mathrm{L}$ of $5-\mu \mathrm{g} / \mathrm{mL}$ antigen in coating buffer (15-mM sodium carbonate and $35-\mathrm{mM}$ sodium bicarbonate, $\mathrm{pH} 9.6)$ at $4^{\circ} \mathrm{C}$ for $12 \mathrm{~h}$ overnight. After three washes with phosphate buffered saline (PBS) $/ 0.05 \%$ Tween- 20 , the plates were blocked with $5 \%$ non-fat milk in $0.05 \%$ Tween-20/PBS solution for $3 \mathrm{~h}$ at room temperature (RT). The test sera (1:200) and peroxidase-conjugated goat antihuman IgG antibodies (1:1000, Zymed, USA) were diluted in blocking buffer. The antigen-coated wells were incubated with serum samples and the secondary antibodies were incubated for $2 \mathrm{~h}$ at RT. Binding was colorimetrically visualized following the addition of $0.04 \% o$-phenylenediamine (Sigma) tablets that were dissolved in $0.012 \% \mathrm{H}_{2} \mathrm{O}_{2}$ /citratephosphate buffer ( $\mathrm{pH} 5$ ) for $15 \mathrm{~min}$ in the dark at $\mathrm{RT}$. $\mathrm{HCl}$
( $2 \mathrm{~N}, 100 \mu \mathrm{L}$ ) was added to the wells to stop the reaction and the optical density (OD) was measured at $490 \mathrm{~nm}$. Cut-off values were calculated as the average OD readings plus two standard deviations.

\section{RESULTS}

An $A$. cantonensis crude antigen-based ELISA was developed to diagnose $A$. costaricensis infections. The sensitivity and specificity of the test were determined by comparing OD readings from the sera of $A$. costaricensis-infected patients to the sera of uninfected controls or patients who were infected with different parasites (Table). Twenty-three out of $26 \mathrm{PC}$ sera had positive OD readings compared to 10 out of 47 sera from patients with other parasitic infections, resulting in a sensitivity of $88.4 \%$ and a specificity of $78.7 \%$ (Figure, Table). When the cut-off values were calculated from $\mathrm{NC}$ absorbance readings, the sensitivity and specificity were $76.9 \%$ and $93.6 \%$ (Table).

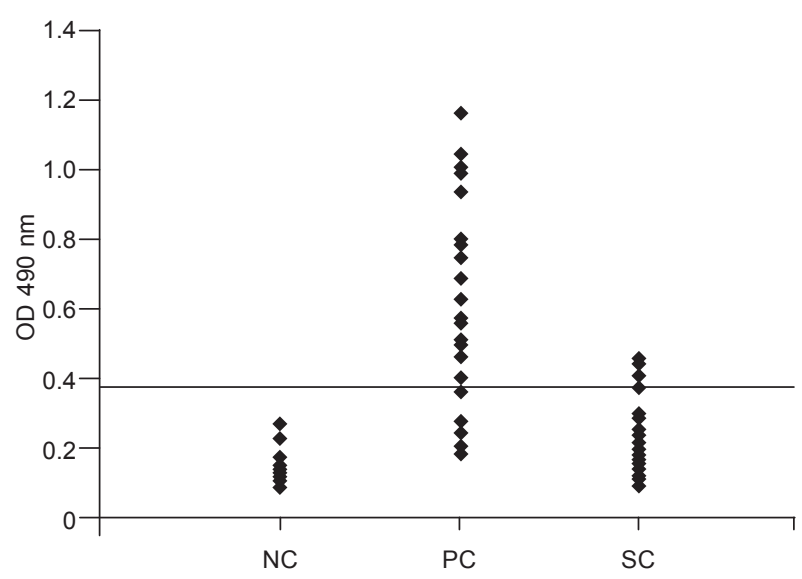

Serum reactivity to Angiostrongylus cantonensis antigens. IgG reactivity to an $A$. cantonensis crude antigen preparation derived from female worms was assessed using serum from normal negative $(\mathrm{NC})(\mathrm{n}=11)$ individuals, patients $(\mathrm{n}=26)$ with histopathological diagnosis of abdominal angiostrongyliasis $(\mathrm{PC})$ or patients $(\mathrm{n}=47)$ with other parasitic infections (SC). Absorbance values were read at $490 \mathrm{~nm}$. The horizontal bar represents the cut-off value established by SC sera reactivity. OD: optical density.

TABLE

Sensitivity and specificity of an Angiostrongylus cantonensis enzyme-linked immunosorbent assay

(ELISA) for the detection of IgG anti-Angiostrongylus costaricensis antibodies

\begin{tabular}{|c|c|c|c|c|c|}
\hline & $\begin{array}{c}\text { Total } \\
\mathrm{n}\end{array}$ & $\begin{array}{c}\text { Positive } \\
n\end{array}$ & $\begin{array}{c}\text { Negative } \\
\mathrm{n}\end{array}$ & $\begin{array}{c}\text { Sensitivity } \\
\%\end{array}$ & $\begin{array}{c}\text { Specificity } \\
\%\end{array}$ \\
\hline \multicolumn{6}{|c|}{ Cut-off: medium optical density +2 standard deviation ${ }^{a}$ of normal control sera } \\
\hline Positive control & 26 & 20 & 6 & 76.9 & - \\
\hline Specificity control & 47 & 3 & 44 & - & 93.6 \\
\hline \multicolumn{6}{|c|}{ Cut-off: medium optical density +2 standard deviation of specificity control sera } \\
\hline Positive control & 26 & 23 & 3 & 88.4 & - \\
\hline Specificity control & 47 & 10 & 37 & - & 78.7 \\
\hline
\end{tabular}

a: optical density at $490 \mathrm{~nm}$. 


\section{DISCUSSION}

A. costaricensis crude antigens have been used for the immunodiagnosis of angiostrongyliasis since 1997 and later in the diagnosis of acute angiostrongyliasis (Graeff-Teixeira et al. 1997, Geiger et al. 2001). Previously used antibody-based detection systems included precipitation reactions (Sauerbrey 1977) and latex agglutination using crude antigenic preparations; the latter has been used for many years in Costa Rica (Kramer et al. 1998). In addition, low molecular weight peptides (Abraham et al. 2004), egg antigens (Mesén-Ramírez et al. 2008) and crude excretion-secretion antigens, as well as host antibody response at both the class (IgE, $\operatorname{Ig} \mathrm{A})$ and isotype (IgG1, IgG2, IgG3, IgG4) (Geiger et al. 2001) levels, have been studied but not extensively evaluated in clinical or epidemiological settings. Due to insufficient sensitivities, specificities and reproducibilities of these assays in diagnosing $A$. costaricensis infections and the unavailability of protocols utilizing purified or recombinant antigens for diagnostic purposes, improvements to currently available crude antigen-based ELISA assays are necessary.

Because $A$. cantonensis and A. costaricensis are congeneric, these organisms likely share various antigenic determinants (Dekumyoy et al. 2000). Furthermore, A. cantonensis can be easily propagated in the laboratory and can thus provide substantial amounts of crude antigen for use in ELISAs. The feasibility of this congeneric species approach has already been demonstrated by the diagnoses of patients who are infected with parasites that share epitopes, such as $S$. stercoralis and Strongyloides venezuelensis (Feliciano et al. 2010) or Strongyloides ratti (Rodrigues et al. 2007). This approach has been particularly promising in the development of alternative methods for the diagnoses of cisticercosis, strongyloidiasis and hidatidosis (Vaz et al. 1997, Sako et al. 2006, Feliciano et al. 2010, Oliveira et al. 2010, da S Ribeiro et al. 2010). In addition, Dekumyoy et al. (2000) studied the use of a crude antigen preparation that was derived from A. costaricensis as a heterologous target for the detection of antibodies in patients with eosinophilic meningitis.

In addition to a potential use for diagnosis, heterologous antigens may also be useful for vaccination strategies that are based on the elicitation of cross-protective immunity (Stropkovská et al. 2010) and the modulation of the immune response (Page et al. 2006). Cross-reactivity or molecular mimicry may elicit the suppression or activation of immune responses that are associated with the pathogenesis of infectious diseases (Kierszenbaum 2003, Gironès et al. 2005, Millington et al. 2006).

The importance of developing molecular diagnostic methods or immunodiagnostic techniques for the diagnosis of human infections with $A$. costaricensis is highlighted by the fact that human cases are difficult to diagnose due to the challenge in identifying trapped larvae (Graeff-Teixeira et al. 1991). For example, a single larva was identified histologically in transit between necrotic intestinal mucosal tissues and the lumen (unpublished observations). More importantly, neither larvae nor eggs have ever been detected in human stool samples and the examination of feces is not routinely performed in the diagnosis of AA.

Compared to a previous report on ELISA using $A$. costaricensis antigen (Geiger et al. 2001), the ELISA using $A$. cantonensis crude antigen preparation in this study showed increased sensitivity ( $76 \%$ in the previous study vs. $88.4 \%$ in this study) and decreased specificity (91.1\% in the previous study vs. $78.7 \%$ in this study). Purified or cloned antigens have not been established as reliable diagnostic tools. Therefore, the use of heterologous antigens may provide a viable alternative for developing an ELISA-based immunodetection system for use in the diagnosis of AA.

\section{REFERENCES}

Abraham ES, Schulz-Key H, Geiger SM 2004. Caracterización de antígenos de bajo peso molecular de Angiostrongylus costaricensis, reconocidos durante una infección experimental en roedores. Parasitol Latinoam 59: 8-13.

Bradford MM 1976. A rapid and sensitive method for the quantitation of microgram quantities of protein utilizing the principle of protein-dye binding. Anal Biochem 72: 248-254.

da S Ribeiro V, Manhani MN, Costa-Cruz JM 2010. IgA detection in human neurocysticercosis using different preparations of heterologous antigen. Parasitol Res 107: 221-225.

Dekumyoy P, Komalamisra C, Nuamtanong S, Nacapunchai D, Sinnawong M, Shanaha P, Piyasatittam P 2000. Angiostrongyliasis: analysis of antigens of Angiostrongylus costaricensis adult worms versus $\operatorname{IgG}$ from infected patients with Angiostrongylus cantonensis. Southeast Asian J Trop Med Public Health 31 (Suppl. 1): 48-53.

Feliciano ND, Gonzaga HT, Gonçalves-Pires M do R, Gonçalves AL, Rodrigues RM, Ueta MT, Costa-Cruz JM 2010. Hydrophobic fractions from Strongyloides venezuelensis for use in the human immunodiagnosis of strongyloidiasis. Diagn Microbiol Infect Dis 67: 153-161.

Geiger SM, Laitano AC, Sievers-Tostes C, Agostini AA, SchulzKey H, Graeff-Teixeira C 2001. Detection of the acute phase of abdominal angiostrongyliasis with a parasite-specific IgG enzyme linked immunosorbent assay. Mem Inst Oswaldo Cruz 96: 515-518.

Gironès N, Cuervo H, Fresno M 2005. Trypanosoma cruzi-induced molecular mimicry and Chagas' disease. Curr Top Microbiol Immunol 296: 89-123.

Graeff-Teixeira C, Agostini AA, Camillo-Coura L, Ferreira-daCruz MF 1997. Seroepidemiology of abdominal angiostrongyliasis: the standardization of an immunoenzymatic assay and prevalence of antibodies in two localities in southern Brazil. Trop Med Int Health 2: 254-260.

Graeff-Teixeira C, Camillo-Coura L, Lenzi HL 1991. Histopathological criteria for the diagnosis of abdominal angiostrongyliasis. Parasitol Res 77: 606-611.

Kierszenbaum F 2003. Views on the autoimmunity hypothesis for Chagas disease pathogenesis. FEMS Immunol Med Microbiol 37: 1-11.

Kramer MH, Greer GJ, Quiñonez JF, Padilla NR, Hernández B, Arana BA, Lorenzana R, Morera P, Hightower AW, Eberhard ML, Herwaldt BL 1998. First reported outbreak of abdominal angiostrongyliasis. Clin Infect Dis 26: 365-372. 
Mesén-Ramírez P, Abrahams-Sandí E, Fernández-Quesada K, Morera P 2008. Angiostrongylus costaricensis egg antigen for the immunodiagnosis of abdominal angiostrongyliasis. J Helminthol 82: 251-254.

Millington OR, Di Lorenzo C, Phillips RS, Garside P, Brewer JM 2006. Suppression of adaptive immunity to heterologous antigens during Plasmodium infection through hemozoin-induced failure of dendritic cell function. J Biol 5: 5 .

Oliveira HB, Machado GA, Mineo JR, Costa-Cruz JM 2010. Taenia saginata metacestode antigenic fractions without affinity to concanavalin A are an important source of specific antigens for the diagnosis of human neurocysticercosis. Clin Vaccine Immunol 17: 638-644.

Page KR, Scott AL, Manabe YC 2006. The expanding realm of heterologous immunity: friend or foe? Cell Microbiol 8: 185-196.

Pena GP, Andrade Filho J, de Assis SC 1995. Angiostrongylus costaricensis: first record of its occurrence in the state of Espírito Santo, Brazil, and a review of its geographic distribution. Rev Inst Med Trop Sao Paulo 37: 369-374.

Rodrigues RM, de Oliveira MC, Sopelete MC, Silva DA, Campos DM,
Taketomi EA, Costa-Cruz JM 2007. IgG1, IgG4, and IgE antibody responses in human strongyloidiasis by ELISA using Strongyloides ratti saline extract as heterologous antigen. Parasitol Res 101: 1209-1214.

Sako Y, Nakao M, Nakaya K, Yamasaki H, Ito A 2006. Recombinant antigens for serodiagnosis of cysticercosis and echinococcosis. Parasitol Int 55 (Suppl.): 69-73.

Sauerbrey M 1977. A precipitin test for the diagnosis of human abdominal angiostrongyliasis. Am J Trop Med Hyg 26: 1156-1158.

Stropkovská A, Janulíková J, Varecková E 2010. Trends in development of the influenza vaccine with broader cross-protection. Acta Virol 54: 7-19.

Vaz AJ, Nunes CM, Piazza RM, Livramento JA, Da Silva MV, Nakamura PM, Ferreira AW 1997. Immunoblot with cerebrospinal fluid from patients with neurocysticercosis using antigen from cysticerci of Taenia solium and Taenia crassiceps. Am J Trop Med Hyg 57: 354-357.

Wang QP, Lai DH, Zhu XQ, Chen XG, Lun ZR 2008. Human angiostrongyliasis. Lancet Infect Dis 8: 621-630. 